\title{
Enhanced gold nanoparticle-tumor cell recognition by albumin multilayer coating
}

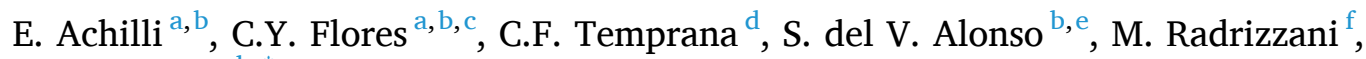 \\ M. Grasselli a,b,* \\ ${ }^{a}$ Universidad Nacional de Quilmes, Dpto. de Ciencia y Tecnología, Laboratorio de Materiales Biotecnológicos (LaMaBio). (B1876) Bernal, Buenos \\ Aires, Argentina \\ b IMBICE (CONICET). GBEyB (Grupo Vinculado en Biología Estructural y Biotecnología), La Plata, Argentina \\ ${ }^{\mathrm{c}}$ Universidad Nacional Arturo Jauretche, Instituto de Ciencias de la Salud. (B1888) Florencio Varela, Buenos Aires, Argentina \\ ${ }^{\mathrm{d}}$ Universidad Nacional de Quilmes, Dpto. de Ciencia y Tecnología, Laboratorio de Inmunología y Virología (LIV) - CONICET. (B1876BXD) Bernal, \\ Buenos Aires, Argentina \\ e Universidad Nacional de Quilmes, Dpto. de Ciencia y Tecnología, Laboratorio de BioNanotecnología (LBN). (B1876BXD) Bernal, Buenos Aires, \\ Argentina \\ ${ }^{\mathrm{f}}$ Universidad Nacional de San Martín, Laboratorio de Neuro y Citogenética Molecular. (B1650) San Martín, Buenos Aires, Argentina
}

\section{A R T I C L E I N F O}

\section{Keywords:}

Gold nanoparticles

Albumin

Protein corona

Bombesin

\begin{abstract}
A B S T R A C T
Background: In a biological environment, nanoparticles are rapidly coated with serum proteins, which affects the NPs transport through biological medium, cellular uptake and response, all of which can impair therapeutic efficiency. Reduction of non-specific adsorption of proteins is mandatory to overcome this drawback.

Aim: We propose to use albumin to prepare a multilayer coating of NPs to reduce the non-specific protein interactions in biological media.

Materials \& methods: Biohybrid NPs (bioHNPs) prepared by coating gold NPs with a multilayer of albumin and finally decorated with Bombesin-related peptides (BD-bioHNPs).

Results: BioHNPs/biological media interaction was characterized by physicochemical and biological techniques under near-physiological conditions. A significant reduction of the Corona effect and enhanced in vitro uptake to PC-3 cells was demonstrated for BD-bioHNPs.

Conclusion: This methodology to prepare decorated bioHNPs allows the preparation of 'stealth' NPs with improved cell targeting and the ability to avoid non-specific interactions with the biological media.
\end{abstract}

\section{Background}

A 2018 report on the worldwide burden of disease for cancer estimated the number of new cancer cases at 18.1 $\mathrm{m}$ [1]. This staggering figure is compelling enough to have launched many investigations on therapeutic drug design strategies related to diagnosing and treating this disease. Although significant advances have been made in these fields, at present, none of the existing therapies can cover all cancer variants, which differ in their histopathological characteristics and their genetic variations [2]. Besides,

\footnotetext{
* Corresponding author: Laboratorio de Materiales Biotecnológicos (LaMaBio), Dpto. de Ciencia y Tecnología, Universidad Nacional de Quilmes, Roque Saenz Pena 352, (B1876) Bernal, Buenos Aires, Argentina.

E-mail address: mariano.grasselli@unq.edu.ar (M. Grasselli).
}

https://doi.org/10.1016/j.onano.2021.100033

Received 13 September 2021; Received in revised form 15 November 2021; Accepted 1 December 2021

Available online 3 December 2021

2352-9520/C 2021 Published by Elsevier Inc. This is an open access article under the CC BY-NC-ND license

(http://creativecommons.org/licenses/by-nc-nd/4.0/). 
many of the available drugs are unable to reach the site of metastases [3].

Approaches based on nanotechnology for the development of novel therapeutic and diagnostic strategies are currently under study. In addition, the use of inorganic materials proposed by nanotechnology opens new alternatives based on the properties of high atomic weight elements at the nanoscale. Nanomaterials are endowed with the unique optical and magnetic characteristics of inorganic nanomaterials, which renders them ideal candidates for cancer therapy [4,5], imaging [6,7], and potential theranostic tools [8-10].

Nanoparticles (NPs) are the most widely studied nanomaterials for nanomedicine applications. There is an abundant body of literature on NP targeting using surface immobilization of different molecules such as vitamins [11,12], peptides [13,14], proteins [15], oligonucleotides [16,17], among others. In addition, these nano-constructs have demonstrated selectivity for specific cell targeting using in vitro cell cultures, running binding experiments in the absence of proteins in the media. However, it is well-known that NPs prepared from inorganic materials and polymers rapidly get coated by serum proteins in a biological environment. This dynamic and complex coating process is called the Corona effect $[18,19]$. One of the main issues pertaining to this process is that it affects the transport of NPs through biological media and cellular uptake, including the cellular response, which can impair therapeutic efficiency significantly [20]. This phenomenon can be explained by thermodynamics, since energy-favored protein binding reduces enthalpy, and the displacement of the hydration layer increases entropy. The consequences of such bio-nano interactions are the increment in the nanoparticle solubility and the possible onset of the biophysical processes of protein misfolding and aggregation. Therefore, the Corona effect masks the chemical or biological functionalities imparted to the NP prepared in the laboratory [21]. The inability to control the NP transport inside the body poses a significant limitation for using nanotechnology to diagnose and treat cancer [22].

Regarding the different materials available for NP preparation, protein-based NPs have shown high biocompatibility and those prepared from albumin have been approved for human therapeutic use [23]. Albumin-based NPs have been designed on account of their various clinical uses, among them, as nano-vehicles in a drug delivery system. Such choice relies on the fact that albumin constitutes approximately $50 \%$ of the proteins present in the plasma of healthy individuals. This multifunctional protein can bind to and transport numerous endogenous and exogenous compounds. Moreover, it is found in large amounts in the circulatory system and extracellular space; however, it is absent in the cell cytoplasm. It is a protein with high biocompatibility and biodegradation to single amino acids [24]. The highlight of albumin-based NPs for the pharmaceutical industry was the conjugation of nanoparticle albumin-bound Paclitaxel (Abraxane ${ }^{\circledR}$ ), which avoids some toxicities associated with solvent-bound Paclitaxel. This NP does not have any specific ligand decoration for targeting; nevertheless, some accumulation in tumors has been described by the 'Improved permeability and retention effect,' also called EPR [25]. Years later, this phenomenon generated controversies in the scientific community since studies show contradictory results [26,27].

More than one decade after the approval of Abraxane $\AA$, few advances have been made to improve the selectivity of this nanocarrier to in vivo address tumor cells by decoration with specific ligands. One possible explanation can be found in the non-covalent interactions between its components, which allow albumin exchange with the milieu. Therefore, any NP decoration will be lost from their surface when NPs are injected into the bloodstream. A recent review stresses the importance of endowing a 'biological identity' to synthetic NPs as an approach to improve the crosstalk with the biological milieu [19]. However, to the best of our knowledge, there are no procedures for preparing stable 'stealth' nanoparticles based on albumin.

Early in the bio-nanotechnology era, it was reported that pre-coating the polystyrene nanosphere with albumin reduces their in vivo receptor-mediated hepatic disposition [28]. However, the dynamic exchange process between the biological media and non-covalent nano-constructs, such as pre-coating or aging NP surface with proteins, spoiled the idea of proteins as coating molecules. Protein gold NPs interactions occur spontaneously, increasing their colloidal stability. However, this interaction is not covalent, and proteins are released from the surface and exchanged with the milieu in proteinaceous media. Besides, proteins can modify their conformation through interaction, and they could adopt a different conformation after being released. It has been demonstrated that albumin is 'spread' onto the gold surface, where at least 12 Au-thiol bounds contribute to albumin binding. The high flexibility of the albumin structure allows significant changes on its surface [29]. Therefore, in addition to the protein exchange effect, the AuNPs coated with a monolayer of albumin (MNPs) will expose a different topography to the medium even if it is the same protein; with a consequent loss of the native conformation, as it has been schematized in MNPs of Fig. 1 scheme. It is important to stress the fundamental importance of

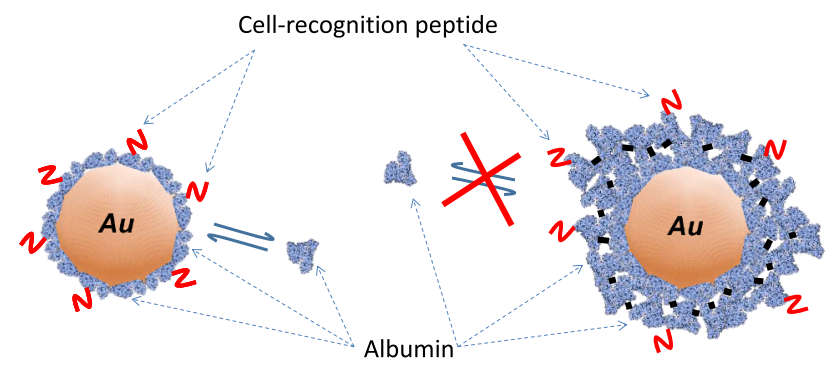

MNPs

bioHNPs

Monolayer Albumin coating

Multilayer Albumin coating

Fig. 1. Scheme of monolayer albumin coating of AuNPs (MNPs) and multilayer albumin coating of AuNPs (bioHNPs). 
protein folding in its biological functionality (in this case, protein-protein interactions). Unfolded proteins or those incorrectly folded will lead to protein malfunction in living systems and biological disorders [30]. To overcome this drawback, gold NPs can be coated with a crosslinked multilayer of albumins as a strategy to produce a highly compact protein shell preserving the albumin surface of the most external layer of the nano-construct, as it is schematized in Fig. 1. Albumin multilayer coating is performed by the radiation-induced crosslinking method [31].

In addition to the compatibility of the bioHNPs with proteinaceous milieu, the nano-construct should be decorated for precise cell targeting. A specific interaction of NPs with cells is essential to develop theranostic tools which can overcome the existing limitations in the delivery of nanostructures [32,33]. Labeled peptides are currently used for in vivo detection of cells containing specific membrane receptors for them [34]. Therefore, the decoration of NPs with particular peptides and the study of the cell-NPs interactions by in vitro experiments are essential checkpoints for the reduction of the Corona effect and finally for the development of a nanomedicine application.

In this report, bioHNPs containing a gold core and a crosslinked multilayer shell of albumins are prepared and characterized in proteinaceous media. Decoration of bioHNPs with a Bombesin-related peptide allows the study of cell uptake in complete media to demonstrate the benefits of the albumin multilayer coating and the specific labeling for cell targeting.

\section{Methods}

Synthesis of gold nanoparticles: AuNPs were prepared according to the Frens method [35]. The concentration of AuNPs was determined through UV-vis spectroscopy, according to Flores et al. [36].

Preparation of hybrid gold/albumin nanoparticles (bioHNPs): AuNPs (500 $\mu \mathrm{l}, 0.1 \mathrm{mM})$ were dispersed in a mixture of BSA/HSA ( $1 \mathrm{ml}$ ) with the final concentration of $30 \mathrm{mg} \mathrm{ml}^{-1}$ of BSA and $15 \mathrm{mg} \mathrm{ml}^{-1}$ of HSA under stirring conditions. After that, absolute ethanol (600 $\mu \mathrm{l}$ ) was added dropwise onto the gold/protein solution, keeping the temperature at $0{ }^{\circ} \mathrm{C}$ under constant stirring. The final concentration of ethanol was $30 \% \mathrm{v} / \mathrm{v}$. The mixture of ethanol, protein, and AuNPs was irradiated with gamma-rays from a ${ }^{60} \mathrm{Co}$ source (PISI CNEA-Ezeiza) at a $10 \mathrm{kGy}$ dose and at a dose rate $1 \mathrm{kGy} \mathrm{h}^{-1}$ and the temperature of the sample was kept in the range of $5-10{ }^{\circ} \mathrm{C}$ during the irradiation.

After irradiation, samples were diluted to a suitable concentration with Milli-Q water for different experiments. NPs were centrifuged $\left(13,000 \mathrm{rpm}, 15 \mathrm{~min}\right.$ at $\left.4{ }^{\circ} \mathrm{C}\right)$, dispersed in Milli-Q water, and treated with $0.05 \%$ glutaraldehyde by stabilization, following, were purified by size-exclusion chromatography as is described previously [37]. The purified NPs were separated by Vivaspin ${ }^{\circledR} 500$ centrifugal concentrator 100,000 MWCO, and free albumin released from bioHNPs was determined by Bradford assay in the supernatant.

In the case of monolayer gold/albumin nanoparticles (MNPs), AuNPs (500 $\mu \mathrm{l}, 0.1 \mathrm{mM}$ ) were dispersed in a final concentration of 1 $\mathrm{mg} \mathrm{ml} \mathrm{m}^{-1}$ of protein. These NPs were not irradiated. Instead, MNPs were purified by centrifuging $\left(13,000 \mathrm{rpm}, 15 \mathrm{~min}\right.$ at $\left.4{ }^{\circ} \mathrm{C}\right)$ and dispersed in Milli-Q water.

Functionalization with synthetic peptide Bombesin-DOTA: bioHNPs were incubated in a solution of glutaraldehyde at $0.02 \%$ freshly prepared in Milli-Q water. The activated bioHNPS were incubated ON with BD at a final concentration of $0.2 \mathrm{mM}$ at room temperature. After incubation, the excess of reagents was removed by Sephadex G-25 (prepacked columns PD-10, GE Healthcare). This desalting column was applied to remove the excess BD.

In vitro protein corona protocol: AuNPs, MNPs, and bioHNPs were incubated in fresh RPMI 1640 medium supplemented with $10 \% \mathrm{v} / \mathrm{v}$ FBS and $0.5 \mathrm{mg} \mathrm{ml}^{-1}$ of HSA. The incubation temperatures tested were at $4 \mathrm{~h}$ and $24 \mathrm{~h}$, at $37{ }^{\circ} \mathrm{C}$ and under a $5 \% \mathrm{CO}_{2}$ atmosphere, simulating cell culture conditions. After the incubation, the samples were centrifuged $\left(13,000 \mathrm{rpm}, 4^{\circ} \mathrm{C}\right)$ for $20 \mathrm{~min}$ and dispersed in water Milli-Q. Using DLS and TEM, sample analysis was performed, comparing the results with the NPs without incubation with FBS.

In vitro study of the NPs interaction with PC-3 cells: Cell culture and NP uptake were performed onto PC-3 cell line (American Type Culture Collection) and maintained in RPMI growth medium at $37^{\circ} \mathrm{C}$ in controlled $\mathrm{CO}_{2}$ atmosphere of $10 \% \mathrm{v} / \mathrm{v}$ FBS (Internegocios, Argentina). The NPs tested were the MNPs and bioHNPs with and without the BD peptide-decoration. For NPs uptake, the protocol developed by Tkachenko et al. was followed [38]. Cells $\left(2 \times 10^{5}\right)$ were seeded in glass coverslips in 24-well plates ON, and after that, incubated with NPs conjugates (10 pM) for $4 \mathrm{~h}$ in the same culture condition. All studies were performed using RPMI media supplemented with $10 \%$ FBS and HSA $\left(0.5 \mathrm{mg} \mathrm{ml}^{-1}\right.$ final concentration). NPs were diluted in the same media. For fluorescence detection experiments, NPs were labeled with NHS ester BODIPY 630/650.

Confocal microscopy pictures were captured with Olympus FV300/BX61 microscope, using sequential Blue Argon (488 nm), Red Helium-Neon (633 nm) excitation lasers, and cut-off emission filters 520/10 and 660, respectively. This combination avoids any possibility of overlapping probes. Olympus Fluoview FV1000 Viewer was used for the analysis of the pictures. Cells were grown onto a coverslip, and after NP incubation, they were rinsed with phosphate-buffered saline (PBS, $10 \mathrm{mM}$, pH 7.4) extensively. Then, cells were fixed with $4 \%$ paraformaldehyde in PBS for $15 \mathrm{~min}$ at $37{ }^{\circ} \mathrm{C}$ and rehydrated in PBS before microscopy analysis. Finally, Syber Green or DAPI was used to stain the cell nucleus.

Flow cytometry analyses were performed with a BD FACSCalibur ${ }^{\circledR}$ cytometer. Briefly, the cells were incubated with a final concentration of $10 \mathrm{pM}$ of NPs for $1 \mathrm{~h}$ or $4 \mathrm{~h}$. After incubation, the cells were washed twice with sterile PBS before analysis. For this assay, the NPs were labeled with the Bodipy FL NHS ester 502/508 chromophore. Data acquisition and analyses were performed using the BD CellQuest Pro-software package. Flow cytometry analyses were carried out by recording 20,000 events and the fluorescence in the FL1 (530/30 nm band-pass filter) channel was analysed. Three independent assays were performed, and the geometric fluorescence media in the FL1 histogram was calculated. The statistical analysis was performed using Graph Pad Prism v6.0 software. The differences between MNPs versus bioHNPs at $37{ }^{\circ} \mathrm{C}$ were analyzed by a two-way ANOVA followed by a post-test of multiple Sidak comparisons. 
Labeled NPs-fluorescence of the different samples was compared as in fluorescence per NP to rule out the possibility that the fluorescence variations found in the cells were due to differences in the NPs labeling.

\section{Results}

The BioHNPs employed in this work were prepared by a novel method, which is less harsh than the well-established process of desolvation by organic solvents. The AuNPs employed in this work were incubated in HSA solution $\left(15 \mathrm{mg} \mathrm{ml}^{-1}\right)$, and ethanol was added up to $30 \% \mathrm{v} / \mathrm{v}$ keeping the temperature below $5{ }^{\circ} \mathrm{C}$ throughout the process. This amount of ethanol has previously been reported to induce reversible albumin aggregation [39]. It is crucial to monitor the aggregation conditions carefully in order to avoid irreversible protein denaturation, like Cohn's fractionation of HSA from human sera. In the next step, the NPs were stabilized covalently by a radiation-induced crosslinking method [39,40]. The crosslinking reaction is based on the protein macro radical recombinations generated by solvent radiolysis [41]. Albumin-NPs are generated simultaneously in addition to bioHNPs [36]. Therefore, a purification protocol including centrifuging and size-exclusion chromatography steps was required to prepare a homogenous and stable batch of bioHNPs.

The characterization data corresponding to the bioHNPs and MNPs is summarized in Figs. 2 and 3. The shape of the plasmon and protein absorption peaks of AuNPs, MNPs, and bioHNPs were compared by means of UV-vis spectra (Fig. 2). BioHNPs spectrum clearly showed an absorption peak at $280 \mathrm{~nm}$ corresponding to the albumin coating and a maximum plasmon shift to $530 \mathrm{~nm}$ produced by the protein coating [36]. Theoretical simulations of Mie theory considering a steady coating model have explained the changes in the plasmon extinction. In this model, all NPs will have the same coating thickness for an experimental condition, regardless of the naked NP radii [36]; therefore, the coating process did not increase the heterogeneity of the NP size population. Dynamic light scattering (DLS) measurements of MNPs and bioHNPs showed a mean hydrodynamic diameter (HD) of $28.02+/-0.6 \mathrm{~nm}$ and $77.4+/-0.7 \mathrm{~nm}$, respectively (Fig. 3A and 3B). Transmission electron microscopy (TEM) measurements were performed to assess their properties and morphology (Fig. 3). The TEM images of bioHNPs revealed well dispersed NPs of the following dimensions: NP core diameter $14+/-3$ $\mathrm{nm}$ and a 'light grey' corona with a diameter of $32+/-7 \mathrm{~nm}$ corresponding to the uranyl stain of the albumin multilayer coating (Fig. 3B). The significant difference between the HD and the diameter measured by TEM could be explained by the hydration of albumin in the coating shell. Fig. S1 shows TEM pictures of bioHNPs at different magnifications.

The $\zeta$-potential of bioHNPs in phosphate buffer was $-12.1+/-1.2 \mathrm{mV}$, which is close to MNPs $(-15.0+/-1.0)$ and that corresponding to BSA $(-18.0 \mathrm{mV})$ in the same buffer condition (Table S1) [42]. These values are characteristic of proteins and far from those corresponding to inorganic nanoparticles ( $\zeta$-potential of AuNPs $-38.8+/-0.8 \mathrm{mV}$ ), reinforcing the hypothesis that the nanoparticle surface will behave quite like a protein surface. Further characterization of bioHNPs by Infrared Spectroscopy, SDS-Page electrophoresis, and AFM is included in the Supporting Information (Fig. S2 to S4). Circular Dichroism Spectroscopy analysis of the protein coating demonstrated that albumin kept its secondary structure almost entirely (Fig. S5).

The shell stability of bioHNPs depends on the albumin released by them, which was determined onto a purified fraction of NPs. Free albumin concentration was below the detection limit of the Bradford assay $\left(3 \mu \mathrm{g} \mathrm{ml} l^{-1}\right)$ of albumin. This value corresponded to less than 50 albumin molecules per single bioHNP.

NP stability was studied in a high-salt medium across the changes of the plasmon signal. Coated NPs showed higher stability than naked ones up to $\mathrm{NaCl} 3 \mathrm{M}$, as can be seen in Fig 4. Both coated NPs (MNPs and bioHNPs) were stable in the studied NaCl range;

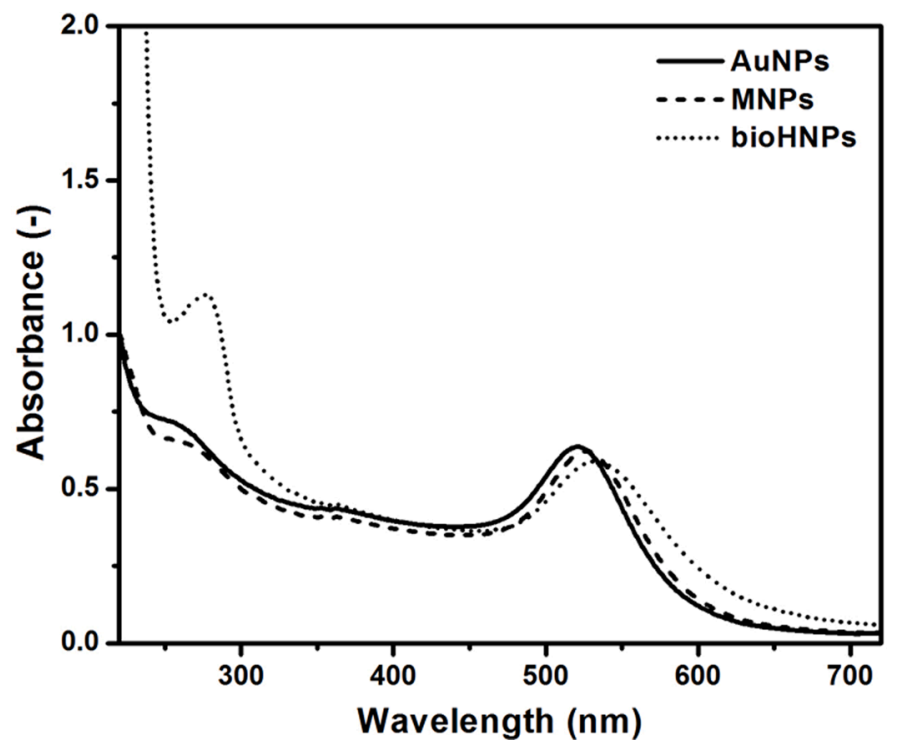

Fig. 2. UV-vis spectra of AuNPs, AuNPs with a monolayer coating of albumin (MNPs) and AuNPs with a multilayer albumin coating (bioHNPs). 
A

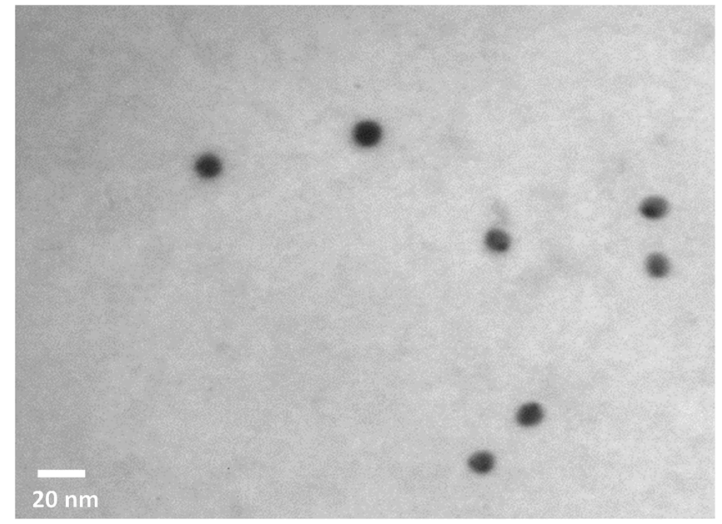

B

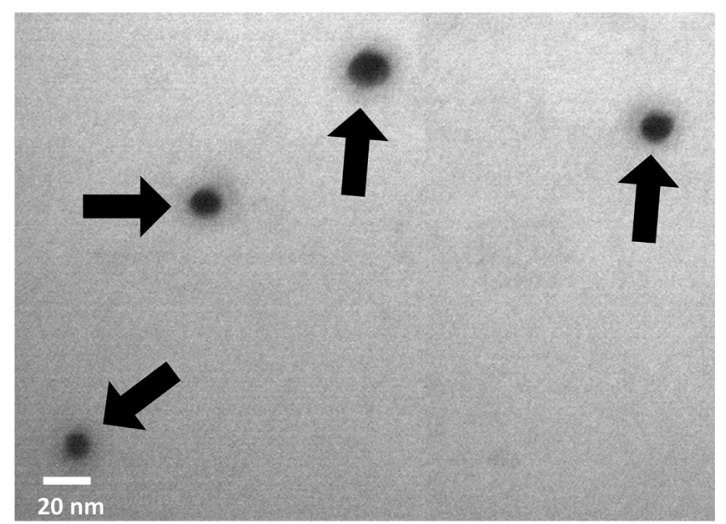

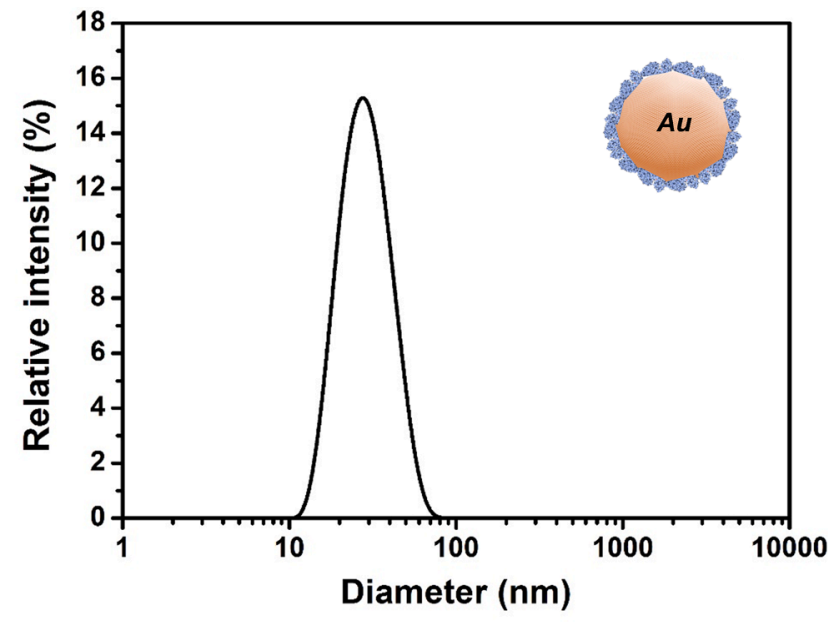

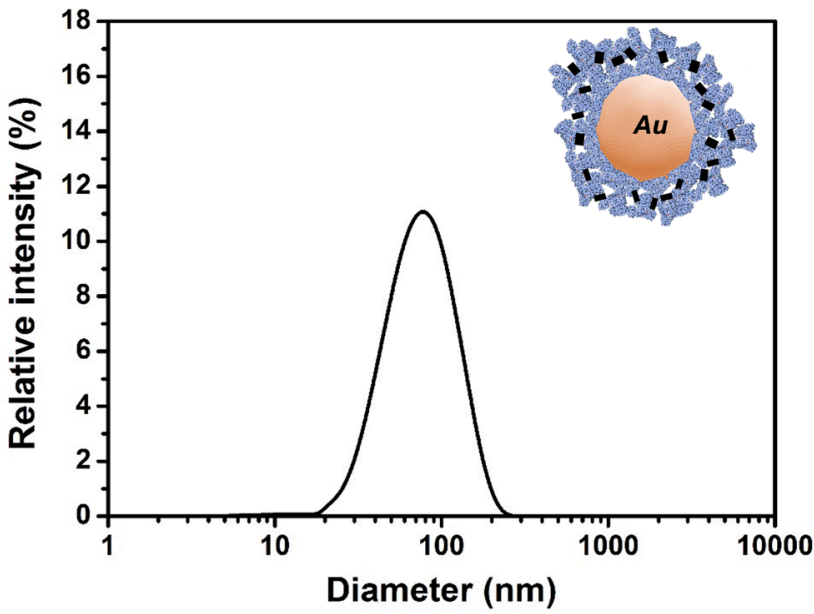

Fig. 3. Size analysis of the A) MNPs and B) bioHNPs by Dynamic light scattering (DLS) and Transmission electron microscopy (TEM). Arrows indicate the multilayer albumin coating.

however, the absorbance ratio at $520 \mathrm{~nm} / 650 \mathrm{~nm}$ or $530 \mathrm{~nm} / 650 \mathrm{~nm}$ was slightly different between MNPs and bioHNPs. This difference stemmed from the changes in the refraction index and thickness of the protein coating layer [36].

In order to study biocompatibility by in vitro experiments, the three NPs were compared in terms of interactions with proteins of a biological medium. Serum proteins stick to NPs when they are dispersed in a proteinaceous medium, forming a protein crown and conferring a new biological identity to them. Therefore, it is essential to analyze the protein corona formation before studying the NP interaction with living cells under realistic conditions.

Considering that most of the blood proteins have HDs between $3 \mathrm{~nm}$ and $15 \mathrm{~nm}$ and NPs have a round shape, it will be possible to assume a protein corona effect by measuring changes in the HD of the NPs. AuNPs (citrate coated), MNPs, and bioHNPs were incubated in a biological media for $4 \mathrm{~h}$ and $24 \mathrm{~h}$ and changes in HDs were measured. The biological media model used was cell culture media (RPMI media, supplemented with FBS $10 \% \mathrm{v} / \mathrm{v}$ ). After removing the vast amount of free protein by centrifuging, the NPs pellet was resuspended in water, and the HDs were measured by DLS. As expected, AuNPs and MNPs showed a considerable increase in their HDs ( $250 \%$ and $49 \%$ respectively at $24 \mathrm{~h}$ ), while bioHNPs did not present a statistical difference in their HD after the incubation during 4 or $24 \mathrm{~h}$. Table 1 summarizes the HD values obtained for all the NPs samples before and after incubation in the biological media. The Corona effect was clearly visible under TEM microscopy. Pictures of NPs after the incubation in the biological medium are shown in Fig. 5. Proteins were visualized by being stained with uranyl acetate. In the case of bioHNPs, it is interesting to observe a lower staining of the protein multilayer coating than that of the free protein present in the sample.

BioHNPs showed low binding to non-specific proteins, so their surface functionalization must ensure cell-recognition properties. For this purpose, bioHNPs were decorated with the Bombesin-related peptide (BD) (see Fig. 6A), and cell targeting was evaluated on in vitro cell culture. BD targets tumor cells containing overexpressed gastrin-release peptide receptor (GRPr), such as the PC-3 cell line [43]. Considering the potential pharmaceutical applications, BD also contains a chelating DOTA moiety, which allows the chelation of therapeutic radioisotopes.

The decoration of bioHNPs was performed using the homo-bifunctional reagent glutaraldehyde. The presence of aromatic amino acids in the BD allowed the visualization of the NPs-decoration by UV-vis spectroscopy (Fig. 6B). In addition, BD was determined in 
A
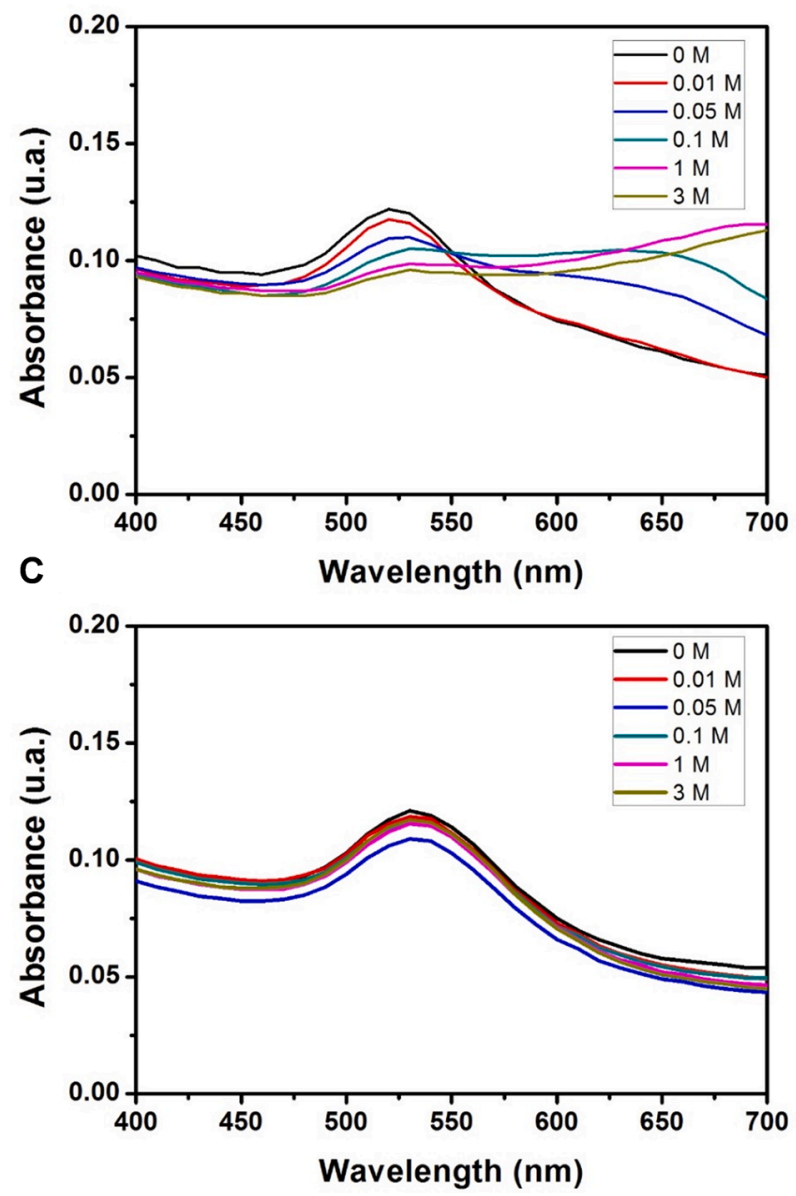

B
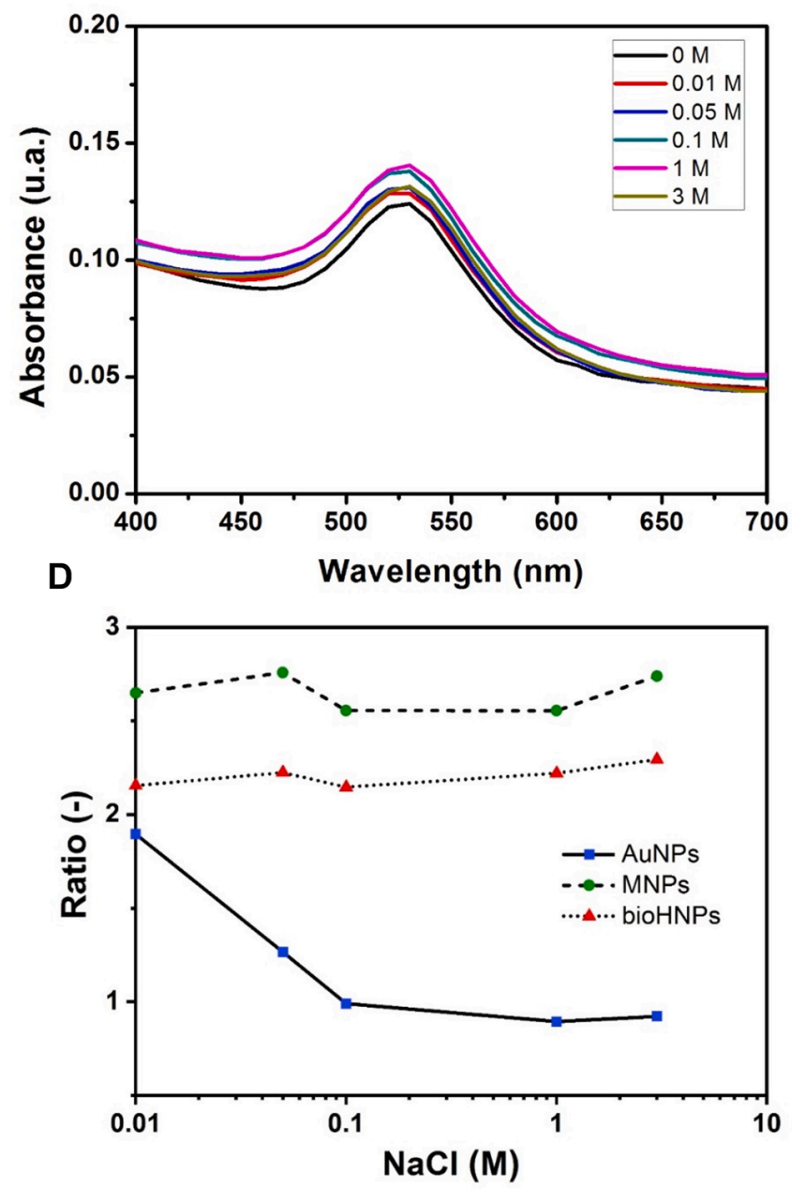

Fig. 4. Stability of nanoparticles at different $\mathrm{NaCl}$ concentrations. (A) Naked (Citrate coated) AuNPs; (B) MNPs and (C) bioHNPs. (D) Evolution of Absorbance ratio $(520 \mathrm{~nm} / 650 \mathrm{~nm}$ or $530 \mathrm{~nm} / 650 \mathrm{~nm})$ with the $\mathrm{NaCl}$ concentration.

Table 1

The hydrodynamic diameter of AuNPs, MNPs, and bioHNPs before and after incubation in a biological media incubation (RPMI + $10 \% \mathrm{SFB}$ ) during different incubation times. Measurements were done in milliQ water after the centrifugation step.

\begin{tabular}{llll}
\hline & $\begin{array}{l}\text { Incubation time* } \\
(\mathrm{h})\end{array}$ & $\begin{array}{l}\text { NP diameter } \\
(\mathrm{nm})+/-1 \mathrm{SD}\end{array}$ & \multicolumn{2}{c}{$\begin{array}{l}\text { Increment } \\
(\%)\end{array}$} \\
\hline \multirow{2}{*}{ AuNPs } & 0 & $21.2+/-1.1$ & 273 \\
& 4 & $78.8+/-5.3$ & 251 \\
\multirow{3}{*}{ MNPs } & 24 & $74.2+/-6.5$ & 54 \\
& 0 & $35.5+/-1.5$ & 49 \\
\multirow{3}{*}{ bioHNPs } & 4 & $54.5+/-2.9$ & 0 \\
& 24 & $52.9+/-3.1$ & $77.4+/-7.0$ \\
\end{tabular}

\footnotetext{
* ) NPs were incubated in fresh RPMI 1640 medium supplemented with $10 \% \mathrm{v} / \mathrm{v} \mathrm{FBS}$ and $0.5 \mathrm{mg} \mathrm{ml}^{-1}$ of $\mathrm{HSA}$ at $37^{\circ} \mathrm{C}$ and under a $5 \% \mathrm{CO}_{2}$ atmosphere.

$\dagger$ ) Diameter determined by DLS after the centrifugation step $\left(13,000 \mathrm{rpm}, 4{ }^{\circ} \mathrm{C}\right)$ for $20 \mathrm{~min}$ to remove the culture media and dispersed in water milliQ.
}

terms of its ability to chelate one $\mathrm{Pb}(\mathrm{II})$ atom per DOTA moiety. Functional BD was quantified by trans-chelation of $\mathrm{Pb}(\mathrm{II})$ [44] following detection by Total reflection X-rays fluorescence (TXRF). This analysis also determined the content of Au and albumin by $\mathrm{S}$ (considering there are $35 \mathrm{~S}$ atoms per albumin). TXRF results showed at least 60 times more albumin in bioHNPs than MNPs, considering all NPs were prepared from the same AuNPs batch. Moreover, the Pb(II) measure determined around 2600 BD molecules 

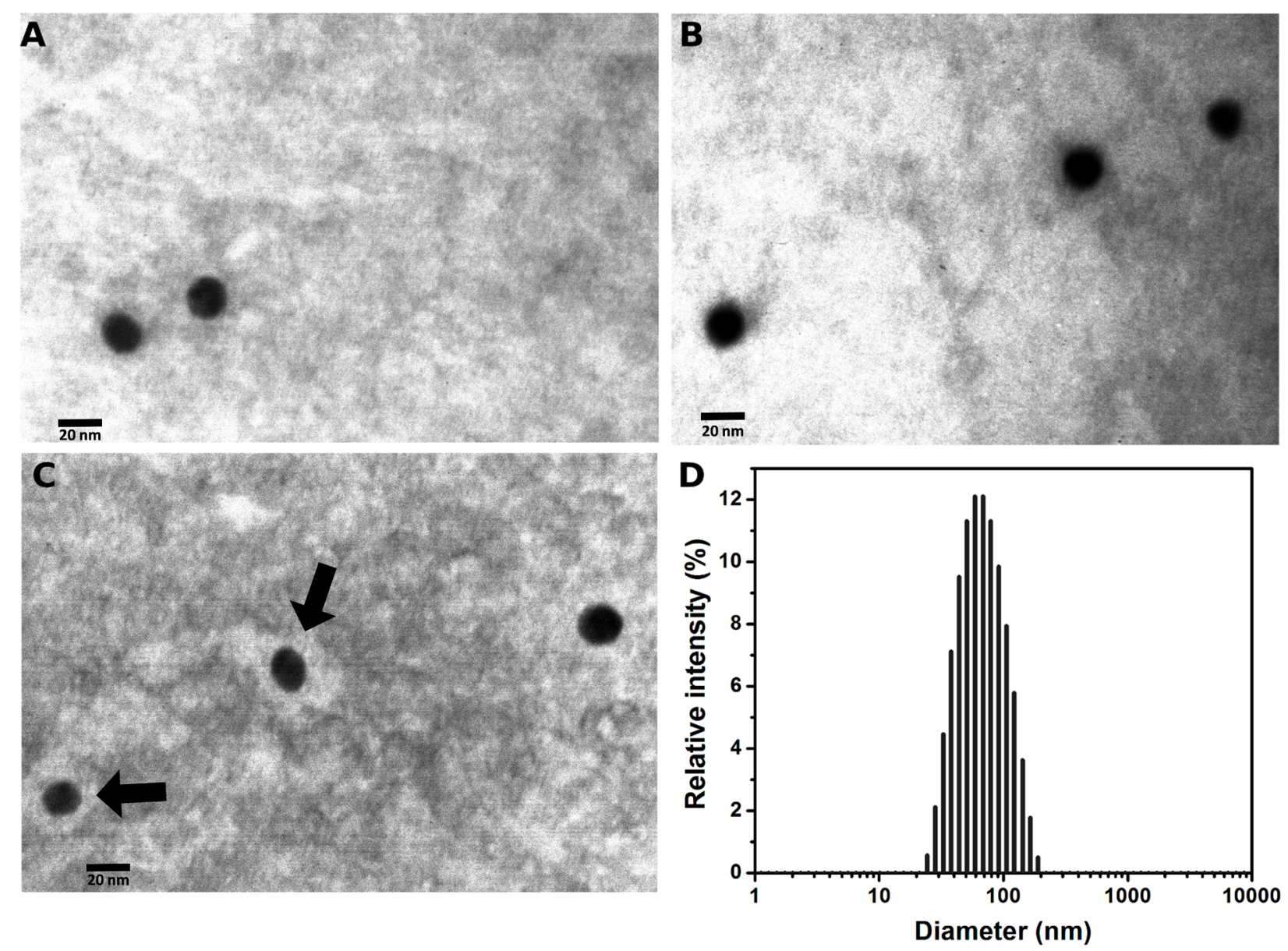

Fig. 5. TEM pictures of naked AuNPs; (B) MNPs and (C) bioHNPs after the incubation in the biological medium. Arrows indicate the multilayer albumin coating. (D) DLS of bioHNPs after the incubation in the biological medium.

per NP (Table S2). The final size of the nano-construct showed a $20-30 \mathrm{~nm}$ increase in the diameter concerning non-BD-decorated bioHNPs (see Fig. S6), confirming the final nano-construct was not oversized.

The study of the biological interaction of prepared NPs with cells was performed by confocal laser-microscopy and flow cytometry analysis using in vitro cell cultures. The choice of model of NPs targeting through Bombesin/GRP receptor interaction was PC-3 cells, which are prostatic tissue cells which grow adherently in a cellular monolayer and have an epithelial morphology [45]. Cell uptake experiments were performed using fluorescent NPs labeled with the chromophore Bodipy 630/650. PC-3 cells were incubated with a final concentration of $10 \mathrm{pM}$ of NPs per well in RPMI culture medium supplemented with $10 \%$ FBS and $0.5 \mathrm{mg} \mathrm{ml}^{-1} \mathrm{HSA}$. After four-hour incubation at $37^{\circ} \mathrm{C}$, cells were rinsed, fixed, and examined by microscopy.

The left column of Fig. 7 shows a comparison of confocal images of PC-3 cells incubated with four types of NPs: MNPs, BD-decorated MNPs (Fig 7A and 7B), bioHNPs and BD-decorated bioHNPs (Fig 7C and 7D) .The nuclei of PC-3 cells are DAPI stained, and red indicates the labeled NPs within the cytoplasmic region. The right column of Fig. 7 shows flow cytometry analysis of statistical data on the uptake.

As can be seen in Fig. 7, cells incubated with the BD-decorated NPs showed more significant red fluorescence when compared to those incubated with non-decorated ones, which suggests cells are not only interacting but also internalizing the peptide signaling. In addition, BD-bioHNPs showed higher fluorescence signal than BD-MNPs. This difference can be clearly visualized in low magnification images (10X) in Fig. S7, which shows pictures corresponding to BD-decorated MNPs and bioHNPs.

NPs/cell interaction observed was minimal for the MNPs (Fig. 7A) and bio-HNPs without peptide decoration (Fig. 7C). In contrast, when NPs were decorated with BD (BD-MNPs and BD-bioHNPs), cell fluorescence values increased, which indicated the presence of NPs. The maximum fluorescence was reached after $4 \mathrm{~h}$ of incubation. Regarding the incubation time, the uptake of BD-MNPs required at least $2 \mathrm{~h}$ to be completed while the uptake of BD-bioHNPs reached its maximum at $1 \mathrm{~h}$. In addition, it was the highest amount of NPs internalized.

The statistical analysis of flow cytometry study, obtained from three independent determinations, is shown in Fig. S9. After $1 \mathrm{~h}$ of incubation MNPs, with or without BD, the result was a significantly different interaction with a $p \leq 0.001$. After $4 \mathrm{~h}$, this difference increased with higher significance $(p<0.0001)$. In the case of bioHNPs, there was a much higher geometric media shift after $1 \mathrm{~h}$ 


\section{A}

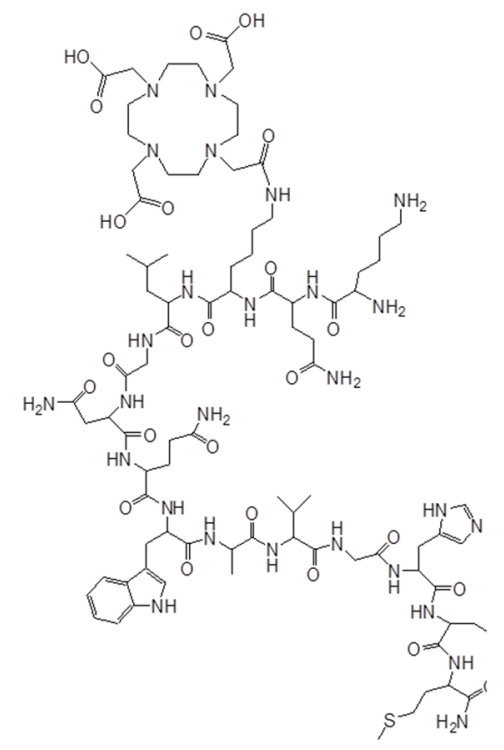

\section{Lys1Lys3(DOTA)-Bombesin1-14}

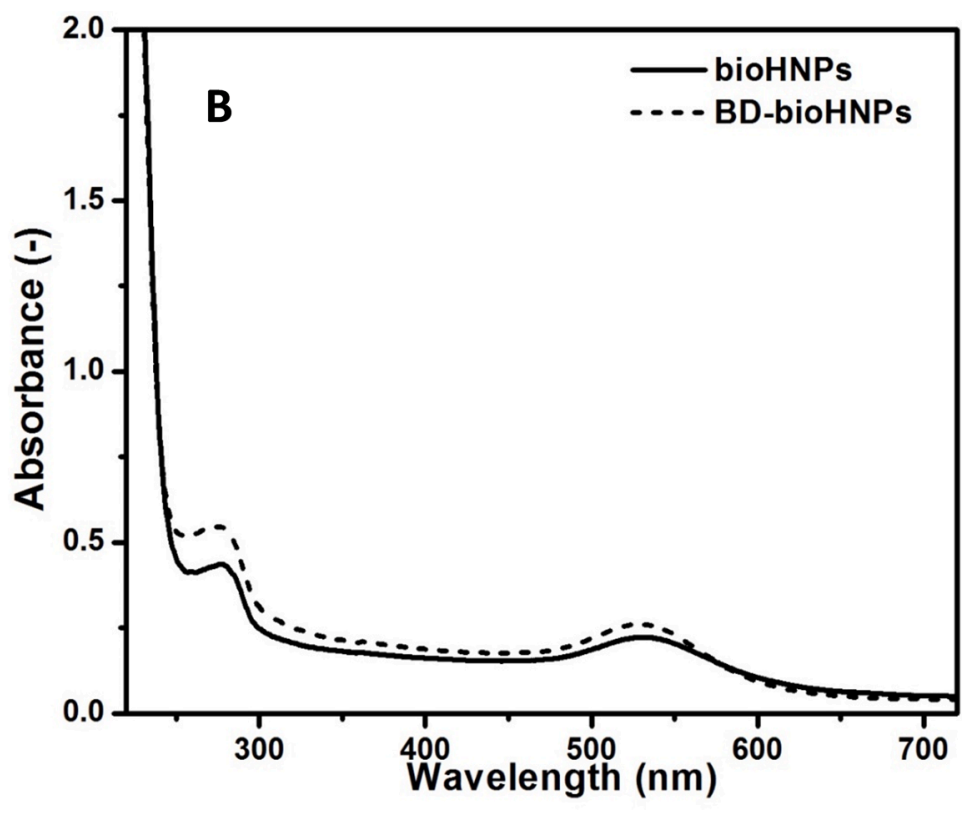

Fig. 6. (A) Scheme of Bombesin-DOTA peptide (BD) used to decorate the bioHNPs and (B) UV-VIS spectra corresponding to bioHNPs and BDdecorated bioHNPs.

incubation time had elapsed. No significant differences were found between non-decorated MNPs and bioHNPs. Both confocal laser microscopy and flow cytometry showed that BD-bioHNPs are the nano-construct that best interacts with PC-3 cells in similar conditions in a biological environment (culture medium with a high concentration of serum proteins).

In order to observe the uptake of NPs in PC-3 cells, phase-contrast microscopy was employed. Cells were incubated for $4 \mathrm{~h}$ with a small amount of NPs (1 pM concentration) of the coated NPs in the monolayer form (MNPs and BD-MNPs) or the hybrid ones (bioHNPs and BD-bioHNPs). Fig. S8 shows selected images of phase-contrast microscopy of cells containing NPs (black dots indicated with arrows). Cultures incubated with BD-MNPs showed NPs near the cell membrane (Fig. S8B). In the case of BD-bioHNPs (Fig. S8D), they were mainly spread in the cytoplasm region.

It is well-known that low temperature can inhibit endocytosis mechanisms [46] so to determine if the endocytic process was energy-driven, NPs cell uptake assays were performed at $5{ }^{\circ} \mathrm{C}$. The interaction was found to be much lower than that observed at $37{ }^{\circ} \mathrm{C}$ (see Fig. S10) with a statistically significant difference $(p \leq 0.0001)$. The assays were performed in the presence of $10 \%$ SFB and HSA to the incubation medium during treatments with BD-bioHNPs.

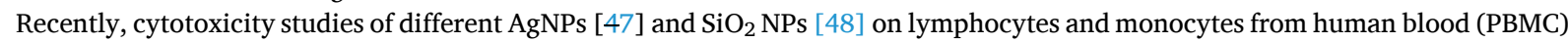
have been reported as model biocompatibility assays. For this reason, the interaction of bioHNPs with PBMC was assessed by means of flow cytometry as a complementary in vitro study of the biocompatibility of these NPs. The flow cytometry analysis showed no interaction after four hours' incubation time (Fig. S11). In this experiment, DB-bioHNPs (i.e. those decorated with Bombesin-DOTA) were not included in the assays because it is known that lymphocytes have GRP receptors on their membranes [49], and some interaction was to be expected.

Cell viability and possible cytotoxic effects on PC-3 cells of non-decorated MNPs and bioHNPs were evaluated by an MTT assay. Cells were incubated at 4, 24, and $48 \mathrm{~h}$ with different MNPs and bioHNPs concentrations (Fig. 8). In all studied conditions, no cytotoxic effects were observed with one exception. A significant decrease in metabolic activity (and therefore cell viability) was observed in cells incubated with MNPs for $48 \mathrm{~h}$ at the highest concentration tested (100 pM). In addition, MNPs aggregation was observed in these wells.

Finally, a human red blood cell hemolysis assay was carried out to evaluate the biocompatibility of non-decorated MNPs and bioHNPs. Cells were incubated for $4 \mathrm{~h}$ with different concentrations of NPs. As a result, no toxicity was observed for any of the conditions and times tested for bioHNPs (see Fig. S12). Low toxicity was determined after incubation with 40 pM of MNPs.

\section{Discussion}

Albumin is the major protein in the human blood, and it is also a commercially available product. These two characteristics allow us to use this biomacromolecule as a building- block to prepare bio nanosystems for nanomedicine.

The ideal NP to create injectable nanomedicines should have low non-specific interacting properties with the biological environment. This feature has proved to be one of the biggest challenges to achieve experimentally. As was mentioned above, albumin has several biological attributes to be used as 'the surface' of the nano-construct. In the past, NP coating with albumin showed biological 

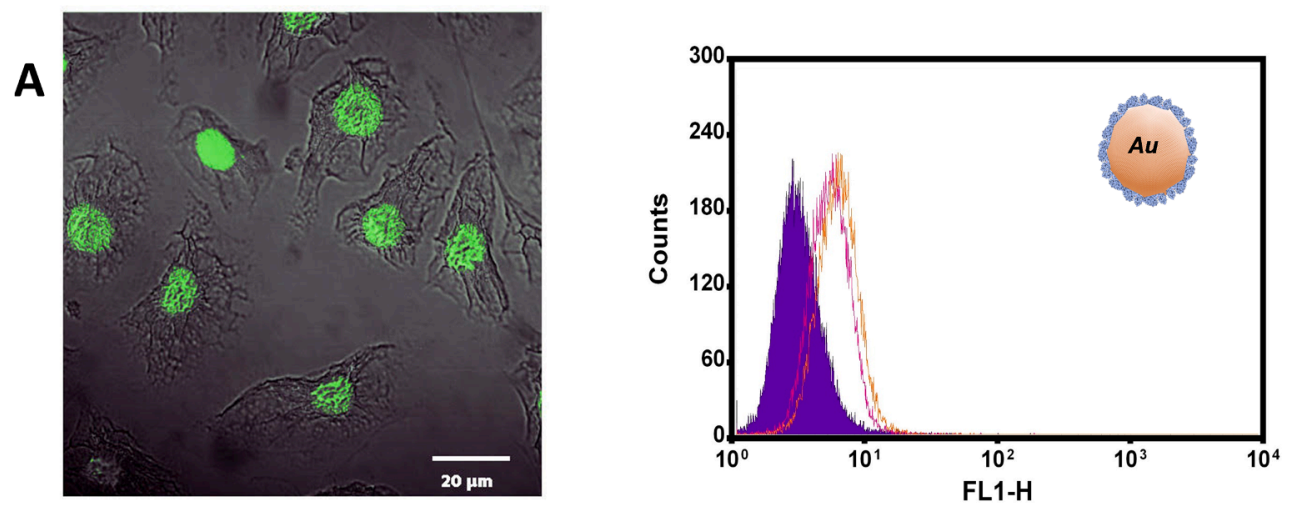

B

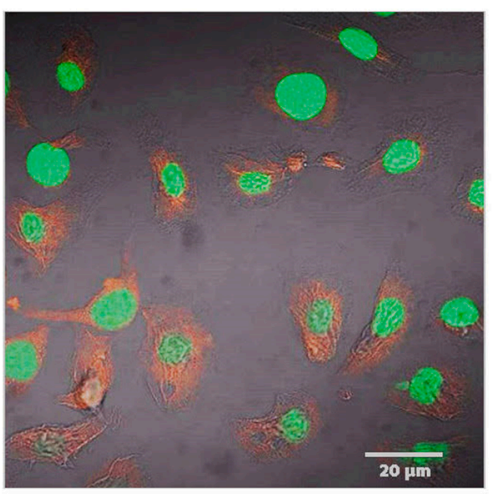

C

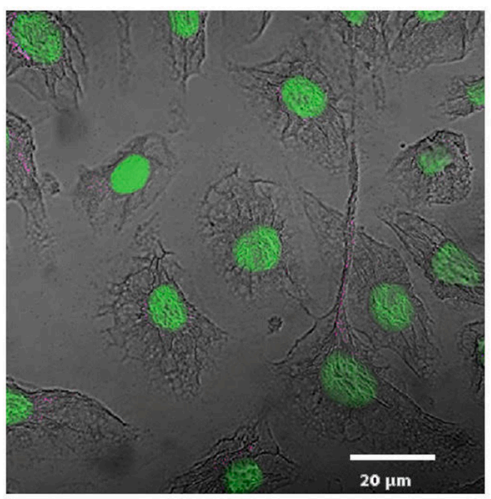

D

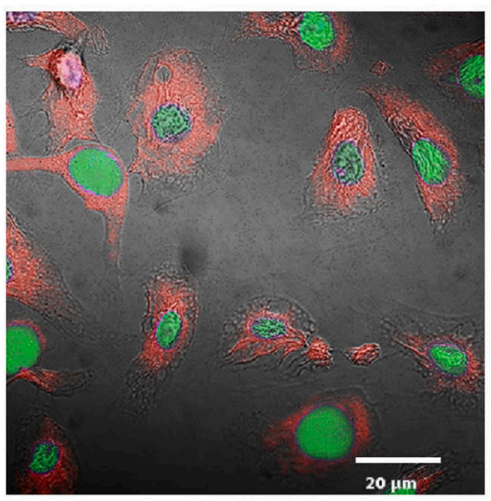

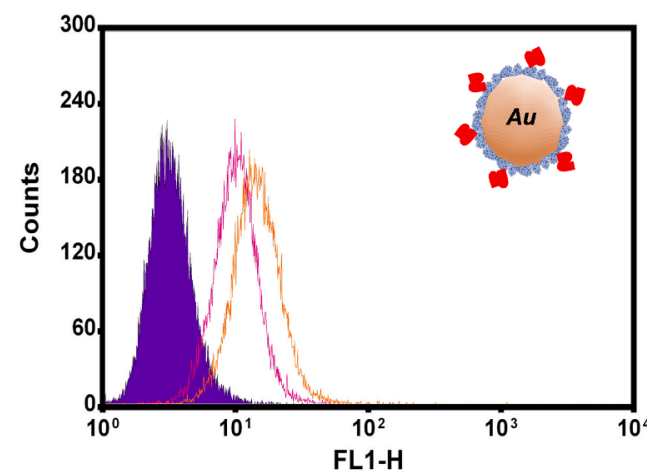


Fig. 7. Confocal microscopy (left column) and flow cytometry histograms (righ column) of PC-3 cells after incubation with fluorescent-labeled NPs. Confocal microscopy was performed after $4 \mathrm{~h}$ of incubation at $37^{\circ} \mathrm{C}$ with $10 \mathrm{pM}$ (60X magnification) and flow cytometry histograms of PC-3 cells incubated with $10 \mathrm{pM}$ of NPs at $37{ }^{\circ} \mathrm{C}$ for $1 \mathrm{~h}$ (fuchsia) and $4 \mathrm{~h}$ (orange) of: A) MNPs; B) BD-MNPs; C) bioHNPs; and D) BD-bioHNPs. (For interpretation of the references to color in this figure legend, the reader is referred to the web version of this article.) 




Time (h)

Fig. 8. In vitro study of the cytotoxicity of MNPs and bioHNPs s in PC-3 cells by MTT assay. Cells were incubated with different concentrations of NPs (in the range $1-100$ pM) for 4, 24, and $48 \mathrm{~h}$. All data are expressed as the percentage respect to non-treated cells control, which was considered as $100 \%$ metabolic activity. Results are shown as the mean +/- SD. Statistics were analyzed using a two-way ANOVA with a 95\% confidence interval $(p<0.05)$.

improvements in most in vitro and in vivo studies [28,50,51]. However, precoating or aging nanoparticle surfaces with proteins (e.g., clustering or serum albumin) could confer NP with stealth properties, but targeting capacity would be reduced [21].

Pharmaceutical technology employed various techniques to prepare hybrid NPs, including covalent conjugation and physical entrapment via coating, spray drying or desolvation, which is one of the most widely applied methods [52]. Desolvation generates a multilayer protein coating in the shape of a core-shell fashion but the high concentration of ethanol or acetone used to yield stable nanostructures can induce protein denaturation [52]. Attention must be paid to the conformational change of macromolecules in the nanostructure though unfortunately to the best of our knowledge, there is little in the existing literature on this aspect. Therefore, if this method is used, the NP surface will not resemble folded albumin in its native state.

In our work, the preparation of BioHNPs was carried out with emphasis on the conservation of the native structure of the most superficial albumins. The multilayer albumin coating of AuNPs prepared by radiation-induced crosslinking method and chemical stabilization allowed a negligible HD increment under proteinaceous media. A similar protein corona experiment performed in the literature using PEG functionalized AuNPs showed a much greater interaction, given that the NP's HD increased by $50 \%$ after $24 \mathrm{~h}$ incubation in serum [53].

Decorated NPs allow targeting of a specific cell type. However, NPs exposed to living cells in a biological medium can be internalized by several mechanisms [54]. Passive internalization occurs without energy requirements or the intervention of receptors. This type of interaction is not selective, so it would not be helpful for targeted therapies. In contrast, decorated bioHNPs can make entry through energy-driven mechanisms, such as endocytosis.

As regards the biological system, BD/GRP receptor, PC-3 cells have been reported as having one unique type of binding site with a high affinity to Bombesin (Kd $9.8 \times 10^{-11} \mathrm{M}$ ) and a binding capacity of 44,000 sites/cell [43]. Therefore, assuming one NP interacts with a dozen membrane receptors in the endocytosis process, the quantity of NPs to saturate the receptors of one cell will be in the order of $10^{2}-10^{3} \mathrm{NPs}$. The in vitro cell uptake assay performed in this work was designed with an average of $2 \times 10^{5}$ cells per well and a maximum of $10^{8}-10^{9} \mathrm{NPs}$ per well to avoid receptor saturation. The experimental NP concentration was set between 1 and $10 \mathrm{pM}$, which corresponds to a total amount of NPs in the range of $6 \times 10^{7}$ to $6 \times 10^{8}$. Thus, the NP/cell ratio was between 300 and 3000 NPs/cells, much lower than the number of GRP receptors. These refined experimental conditions allowed the maximum uptake expression under non-saturating conditions and avoided NPs overloaded experiments.

Results from confocal microscopy and flow cytometry demonstrate the enhanced uptake process of BD-bioHNPs. In addition, taking into account the dissociation constant of Bombesin for GRPr is in the order of 1-10 nM [43,55] and the experiments performed above using pM concentration of bioHNPs, it is possible to speculate that the avidity of the NPs decorated with BD is, at least, three orders of magnitude higher than that of the free peptide (at $37^{\circ} \mathrm{C}$ ). In addition, bioHNPs showed lower cytotoxicity for a longer time than MNPs.

The information given in this work might become extremely useful for those working on nanoparticle design as a cornerstone for the development of future applications in medicine. Remarkably, the strategy of multilayer protein coating can be extrapolated to other inorganic NPs to improve biocompatibility by reducing the Corona effect, enhancing ligand/receptor recognition for cell targeting and reducing unwanted cytotoxicity.

\section{Fundings}

The research leading to these results has received partial funding from IAEA (CRP code F22064); Argentinean grants from the Ministry of Science, Technology and Productive Innovation (MINCYT); and Universidad Nacional de Quilmes (UNQ), Buenos Aires, 
Argentina.

\section{Author agreement}

I certify that all authors have seen and approved the final version of the manuscript being submitted.

I warrant that the article is the authors' original work, hasn't received prior publication and isn't under consideration for publication elsewhere.

\section{CRediT authorship contribution statement}

E. Achilli: Methodology, Investigation, Formal analysis. C.Y. Flores: Methodology, Investigation. C.F. Temprana: Methodology, Formal analysis. S. del V. Alonso: Writing - review \& editing. M. Radrizzani: Investigation. M. Grasselli: Conceptualization, Supervision, Writing - original draft, Writing - review \& editing.

\section{Declaration of Competing Interest}

The authors declare that they have no known competing financial interests or personal relationships that could have appeared to influence the work reported in this paper.

\section{Supplementary materials>}

Supplementary material associated with this article can be found, in the online version, at doi:10.1016/j.onano.2021.100033.

\section{References}

[1] F. Bray, J. Ferlay, I. Soerjomataram, R.L. Siegel, L.A. Torre, A Global cancer statistics 2018: GLOBOCAN estimates of incidence and mortality worldwide for 36 cancers in 185 countries, CA 68 (2018) 394-424.

[2] G.P. Gupta, J. Massagué, Cancer metastasis: building a framework, Cell 127 (2006) 679-695.

[3] C. Van de Wiele, F. Dumont, R.V. Broecke, W. Oosterlinck, V. Cocquyt, R. Serreyn, R.A Dierckx, Technetium-99 m RP527, a GRP analogue for visualisation of GRP receptor-expressing malignancies: a feasibility study, Eur. J. Nucl. Med. 27 (2000) 1694-1699.

[4] N.S. Abadeer, C.J. Murphy, Recent progress in cancer thermal therapy using gold nanoparticles, J. Phys. Chem. C 120 (2016) $4691-4716$.

[5] D.P. Yang, X. Liu, C.P. Teng, C. Owh, K.Y. Win, M. Lin, E Ye, Unexpected formation of gold nanoflowers by a green synthesis method as agents for a safe and effective photothermal therapy, Nanoscale 9 (2017) 15753-15759.

[6] D. Rand, V. Ortiz, Y. Liu, Z. Derdak, J.R. Wands, M. Taticek, C Rose-Petruck, Nanomaterials for X-ray imaging: gold nanoparticle enhancement of X-ray scatter imaging of hepatocellular carcinoma, Nano Lett. 11 (2011) 2678-2683.

[7] T.H. Shin, Y. Choi, S. Kim, J. Cheon, Recent advances in magnetic nanoparticle-based multi-modal imaging, Chem. Soc. Rev. 44 (2015) $4501-4516$.

[8] F.Y. Kong, J.W. Zhang, R.F. Li, Z.X. Wang, W.J. Wang, W. Wang, Unique roles of gold nanoparticles in drug delivery, targeting and imaging applications, Molecules 22 (2017) 1445.

[9] L. Zhu, Z. Zhou, H. Mao, L. Yang, Magnetic nanoparticles for precision oncology: theranostic magnetic iron oxide nanoparticles for image-guided and targeted cancer therapy, Nanomed 12 (2017) 73-87.

[10] J.F. Hainfeld, H.M. Smilowitz, M.J. O'Connor, F.A. Dilmanian, D.N. Slatkin, Gold nanoparticle imaging and radiotherapy of brain tumors in mice, Nanomed 8 (2013) 1601-1609.

[11] A. Shakeri-Zadeh, G.A. Mansoori, A.R. Hashemian, H. Eshghi, A. Sazgarnia, A.R Montazerabadi, Cancerous cells targeting and destruction using folate conjugated gold nanoparticles, Dyn. Biochem. Proc. Biotechnol. Mol. Biol. 4 (2010) 6-12.

[12] H. Samadian, S. Hosseini-Nami, S.K. Kamrava, H. Ghaznavi, A. Shakeri-Zadeh, Folate-conjugated gold nanoparticle as a new nanoplatform for targeted cancer therapy, J. Cancer Res. Clin. Oncol. 142 (2016) 2217-2229.

[13] L. Sun, D. Liu, Z. Wang, Functional gold nanoparticle- peptide complexes as cell-targeting agents, Langmuir 24 (2008) $10293-10297$.

[14] C. Velasco-Aguirre, F. Morales, E. Gallardo-Toledo, S. Guerrero, E. Giralt, E. Araya, M.J. Kogan, Peptides and proteins used to enhance gold nanoparticle delivery to the brain: preclinical approaches, Int. J. Nanomed. 10 (2015) 4919.

[15] P.H. Yang, X. Sun, J.F. Chiu, H. Sun, Q.Y. He, Transferrin-mediated gold nanoparticle cellular uptake, Bioconj. Chem. 16 (2005) $494-496$.

[16] N.L. Rosi, D.A. Giljohann, C.S. Thaxton, A.K. Lytton-Jean, M.S. Han, C.A Mirkin, Oligonucleotide-modified gold nanoparticles for intracellular gene regulation, Science 312 (2006) 1027-1030.

[17] S. Dhar, W.L. Daniel, D.A. Giljohann, C.A. Mirkin, S.J Lippard, Polyvalent oligonucleotide gold nanoparticle conjugates as delivery vehicles for platinum (IV) warheads, J. Am. Chem. Soc. 131 (2009) 14652-14653.

[18] T. Cedervall, I. Lynch, S. Lindman, T. Berggård, E. Thulin, H. Nilsson, K.A. Dawson, S. Linse, Understanding the nanoparticle-protein corona using methods to quantify exchange rates and affinities of proteins for nanoparticles, Proc. Nat. Acad. Sci. 104 (2007) $2050-2055$

[19] M.R. Mohammadi, C. Corbo, R. Molinaro, J.R. Lakey, Biohybrid nanoparticles to negotiate with biological barriers, Small 15 (2019), 1902333.

[20] L. Damalakiene, V. Karabanovas, S. Bagdonas, M. Valius, R. Rotomskis, Intracellular distribution of nontargeted quantum dots after natural uptake and microinjection, Int. J. Nanomed. 8 (2013) 555.

[21] P.C. Ke, S. Lin, W.J. Parak, T.P. Davis, F Caruso, A decade of the protein corona, ACS Nano 11 (2017) 11773-11776.

[22] S. Wilhelm, A.J. Tavares, Q. Dai, S. Ohta, J. Audet, H.F. Dvorak, W.C Chan, Analysis of nanoparticle delivery to tumours, Nat. Rev. Mat. 1 (2016) 1-12.

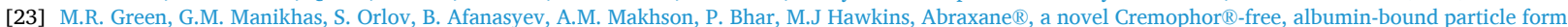
of paclitaxel for the treatment of advanced non-small-cell lung cancer, Ann. Oncol. 17 (2006) 1263-1268.

[24] L.H. Estrada, J.A. Champion, Protein nanoparticles for therapeutic protein delivery, Biomat. Sci. 3 (2015) 787-799.

[25] H. Kobayashi, R. Watanabe, P.L. Choyke, Improving conventional enhanced permeability and retention (EPR) effects; what is the appropriate target? Theranostics 4 (2014) 81.

[26] R. Van der Meel, T. Lammers, W.E. Hennink, Cancer nanomedicines: oversold or underappreciated? Exp. Op. Drug Deliv. 14 (2017) 1-5.

[27] G. Bor, I.D. Mat Azmi, A. Yaghmur, Nanomedicines for cancer therapy: current status, challenges and future prospects, Ther. Deliv. 10 (2019) 113-132. 
[28] K.I. Ogawara, K. Furumoto, S. Nagayama, K. Minato, K. Higaki, T. Kai, T. Kimura, Pre-coating with serum albumin reduces receptor-mediated hepatic disposition of polystyrene nanosphere: implications for rational design of nanoparticles, J. Control Rel. 100 (2004) $451-455$.

[29] L. Wang, J. Li, J. Pan, X. Jiang, Y. Ji, Y. Li, C Chen, Revealing the binding structure of the protein corona on gold nanorods using synchrotron radiation-based techniques: understanding the reduced damage in cell membranes, J. Am. Chem. Soc. 135 (2013) 17359-17368.

[30] C.M. Dobson, Protein folding and misfolding, Nature 426 (2003) 884-890.

[31] C.Y. Flores, E. Achilli, M. Grasselli, Radiation-induced preparation of core/shell gold/albumin nanoparticles, Radiat. Phys. Chem. 142 (2018) 60-64.

[32] E. Polo, M. Collado, B. Pelaz, P Del Pino, Advances toward more efficient targeted delivery of nanoparticles in vivo: understanding interactions between nanoparticles and cells, ACS Nano 11 (2017) 2397-2402.

[33] A. Verma, F. Stellacci, Effect of surface properties on nanoparticle-cell interactions, Small 6 (2010) 12-21.

[34] T. Maina, H. Bergsma, H.R. Kulkarni, D. Mueller, D. Charalambidis, E.P. Krenning, B.A. Nock, M. de Jong, R.P Baum, Preclinical and first clinical experience with the gastrin-releasing peptide receptor-antagonist [68 Ga] SB3 and PET/CT, Eur. J. Nucl. Med. Molec. Imag. 43 (2016) 964-973.

[35] G. Frens, Controlled nucleation for the regulation of the particle size in monodisperse gold suspensions, Nat. Phys. Sci. 241 (1973) $20-22$.

[36] C.Y. Flores, E. Achilli, D.C. Schinca, M Grasselli, Plasmon properties of multilayer albumin/gold hybrid nanoparticles, Mater. Res. Exp. 6 (2019), 055005.

[37] Achilli, E. PhD Thesis, Universidad Nacional de Quilmes, Buenos Aires, Argentina, March 2019. http://ridaa.unq.edu.ar/handle/20.500.11807/1729.

[38] A.G. Tkachenko, H. Xie, Y. Liu, D. Coleman, J. Ryan, W.R. Glomm, M.K. Shipton, S. Franzen, D.L Feldheim, Cellular trajectories of peptide-modified gold particle complexes: comparison of nuclear localization signals and peptide transduction domains, Bioconj. Chem. 15 (2004) 482-490.

[39] E. Achilli, G. Casajus, M. Siri, C. Flores, S. Kadłubowski, S.D.V. Alonso, M Grasselli, Preparation of protein nanoparticle by dynamic aggregation and ionizinginduced crosslinking, Coll. Surf. A 486 (2015) 161-171.

[40] S.L. Soto Espinoza, M.L. Sánchez, V. Risso, E.E. Smolko, M Grasselli, Radiation synthesis of seroalbumin nanoparticles, Radiat. Phys. Chem. 81 (2012) $1417-1421$.

[41] E. Achilli, M. Siri, C.Y. Flores, P.A. Kikot, S. Flor, M. Martinefski, S. Lucangioli, S.D.V. Alonso, M Grasselli, Radiolysis effect of the high proportion of ethanol in the preparation of albumin nanoparticle, Radiat. Phys. Chem. 165 (2019), 108387.

[42] V.L. Vilker, C.K. Colton, K.A Smith, The osmotic pressure of concentrated protein solutions: effect of concentration and pH in saline solutions of bovine serum albumin, J. Colloid Interface Sci. 79 (1981) 548-566.

[43] H. Reile, P.E. Armatis, A.V Schally, Characterization of high- affinity receptors for bombesin/gastrin releasing peptide on the human prostate cancer cell lines PC-3 and DU-145: internalization of receptor bound ${ }^{125} \mathrm{I}-\left(\mathrm{Tyr}^{4}\right)$; bombesin by tumor cells, Prostate 25 (1994) 29-38.

[44] E. Dadachova, L.L. Chappell, M.W Brechbiel, Spectrophotometric method for determination of bifunctional macrocyclic ligands in macrocyclic ligand-protein conjugates, Nucl. Med. Biol. 26 (1999) 977-982.

[45] J.M. Siegfried, N. Krishnamachary, A.G. Davis, C. Gubish, J.D. Hunt, S.P. Shriver, Evidence for autocrine actions of neuromedin B and gastrin-releasing peptide in non-small cell lung cancer, Pulm. Pharmacol. Therap. 12 (1999) 291-302.

[46] T. Mironava, M. Hadjiargyrou, M. Simon, V. Jurukovski, M.H. Rafailovich, Gold nanoparticles cellular toxicity and recovery: effect of size, concentration and exposure time, Nanotoxicol 4 (2010) 120-137.

[47] S. Pourhoseini, R.T. Enos, A.E. Murphy, B. Cai, J.R Lead, Characterization, bio-uptake and toxicity of polymer-coated silver nanoparticles and their interaction with human peripheral blood mononuclear cells, Beilstein J. Nanotechnol. 12 (2021) 282-294.

[48] A. Mendoza, J.A. Torres-Hernandez, J.G. Ault, J.H. Pedersen-Lane, D. Gao, D.A Lawrence, Silica nanoparticles induce oxidative stress and inflammation of human peripheral blood mononuclear cells, Cell Stress Chaperones 19 (2014) 777-790.

[49] M. Del Rio, A. Hernanz, M.B. De La Fuente, gastrin-releasing peptide, and neuromedin C modulate murine lymphocyte proliferation through adherent accessory cells and activate protein kinase C, Peptides 15 (1994) 15-22.

[50] Q. Peng, S. Zhang, Q. Yang, T. Zhang, X.Q. Wei, L. Jiang, C.L. Zhang, Q.M. Chen, Z.R. Zhang, Y.F Lin, Preformed albumin corona, a protective coating for nanoparticles based drug delivery system, Biomaterial 34 (2013) 8521-8530.

[51] J. Mariam, S. Sivakami, P.M. Dongre, Albumin corona on nanoparticles-a strategic approach in drug delivery, Drug Deliv. 23 (2016) 2668-2676.

[52] A.O. Elzoghby, W.M. Samy, N.A. Elgindy, Albumin-based nanoparticles as potential controlled release drug delivery systems, J. Contr. Rel. 157 (2012) $168-182$.

[53] A. Gupta, D.F. Moyano, A. Parnsubsakul, A. Papadopoulos, L.S. Wang, R.F. Landis, R. Das, V.M Rotello, Ultrastable and biofunctionalizable gold nanoparticles, ACS Appl. Mat. Interf. 8 (2016) 14096-14101.

[54] N.M. Zaki, N. Tirelli, Gateways for the intracellular access of nanocarriers: a review of receptor-mediated endocytosis mechanisms and of strategies in receptor targeting, Exp. Op. Drug Deliv. 7 (2010) 895-913.

[55] S.M. Okarvi, I.A. Jammaz, Preparation and evaluation of bombesin peptide derivatives as potential tumor imaging agents: effects of structure and composition of amino acid sequence on in vitro and in vivo characteristics, Nucl. Med. Biol. 39 (2012) 795-804. 